\title{
Operation Gritrock: Christmas bulletin from UK army medics in Sierra Leone
}

\author{
Several months into their mission to the Ebola epidemic in Sierra Leone, how are the UK army \\ medics faring? There have been teething problems, admit Lieutenant Colonel Andrew Johnston \\ and colleagues, but the quality of care and levels of motivation are high
}

\section{Andrew Johnston consultant in respiratory and intensive care medicine, Royal Centre for Defence Medicine, Queen Elizabeth Hospital, Birmingham, and lieutenant colonel, Royal Army Medical Corps, Mark Bailey consultant in infectious diseases and lieutenant colonel, Royal Army Medical Corps, Simon Horne consultant in emergency medicine}

\begin{abstract}
The UK contribution to the Ebola epidemic in west Africa has been run by the Department for International Development, with major support from the British military. We now have around 800 troops in Sierra Leone including the primary casualty receiving ship the RFA (Royal Fleet Auxiliary) Argus offshore as a logistic support platform. Soldiers from the UK Royal Engineers have built seven Ebola treatment centres (ETCs) and, at the time of writing, four have been taken over by non-governmental organisations and are open or close to opening.
\end{abstract}

\section{Range of nationalities and staff}

In the UK the Army Medical Services Training Centre has trained numerous military personnel, including 90 British and 40 Canadian military clinical staff and administrators. A significant number of civilian healthcare workers have completed the training; 50 from the UK, 20 Norwegians, and 20 Danes. All went through a comprehensive training package covering clinical care, personal protective equipment, and numerous other aspects such as the personal and team resilience required to safely deploy.

These staff are now deployed or about to deploy to various ETCs around Sierra Leone. These teams comprise doctors, nurses, military medics, and administrators, many with experience of working overseas in difficult conditions. All are incredibly motivated and enthusiastic to get out to Sierra Leone as soon as possible and start treating patients. Other civilian teams have been trained elsewhere in the UK by various charities.

How is it going on the ground? Four hundred UK funded beds are now built, and will open as staffing increases. With military assistance Save the Children has half of their beds open at Kerry Town in the south of the Freetown peninsula. The military staffed treatment facility at Kerry Town has 16 beds available and plans to expand to 24 beds by January 2015 . These beds are available to provide high quality treatment for health care workers. Our laboratory is providing blood chemistry, haematology, and coagulation testing as well as blood culture and novel polymerase chain reaction systems that can rapidly identify a large number of bacterial species before conventional culture could do so. It has also provided blood products to treat patients with coagulopathy. Very few other ETCs are able to offer this level of care.

\section{Media criticism}

We have not got everything right. There has been criticism in the media for the low number of beds that have been available in British funded ETCs. Mobilising, training, and deploying sufficient staff to safely care for patients with Ebola is very difficult and takes time. Operating in west Africa is complicated by the austere environment, difficult logistics, and endemic diseases. Even organisations experienced in treating Ebola patients are struggling to cope. As our first military clinical team near the end of their deployment a new team will be deploying before Christmas and we are confident the Kerry Town ETC will continue to provide world class care to international health care workers and Sierra Leonean workers based in UK funded ETCs. Major challenges remain, such as liaising with local healthcare units to ensure eligible patients are referred to us as soon as possible, and assisting Save the Children to reach full operational capacity. As resources expand we hope to roll out the capability to allow any health care worker to be treated in our military facility. Finally, as public and clinical awareness of our ability to provide a high standard of care increases, including intravenous fluids, central venous access, electrolyte replacement and advanced diagnostics, we hope more patients will access the military staffed ETC.

Mark Bailey will be returning to the UK in a few weeks and will train subsequent military cohorts for deployment. In Kerry Town Andy Johnston will be working as a physician intensivist and Simon Horne as deployed medical director. 
The BMJ has chosen Médecins Sans Frontières as its 2014 Christmas charity. Find out how to donate at http://bit.ly/12pPyH3. Many thanks for your support.

Access all The BMJs content on the ongoing Ebola outbreak at thebmj. com/ebola.
Cite this as: BMJ 2014;349:g7721

๑ BMJ Publishing Group Ltd 2014 